Ballestero, A. (2017). Capacity as Aggregation: Promises, Water and a Form of Collective Care in Northeast Brazil. The Cambridge Journal of Anthropology, 35(1), 31-48. https://doi.org/10.3167/cja.2017.350104

\title{
Capacity as Aggregation \\ Promises, Water and a Form of Collective Care in Northeast Brazil
}

Andrea Ballestero, Rice University [ORCID: 0000-0001-7692-0514]

\begin{abstract}
As the twenty-first century gets underway, people have been experimenting with many forms of political organization. In Northeast Brazil, that experimental spirit led to the creation of the Water Pact, a process involving more than eight thousand participants through a series of public promise-making rituals in which they made pledges to care for water, attending to the specificities of their own context. The Pact gathered those promises into a multi-scalar formation that, the organizers believed, would yield the necessary resources to address the state's water problems. The Pact would break with an unsuccessful history of infrastructural and legal reforms concerning deep-water access in the state of Ceará. This article examines how that collective was produced, what its constituent units were and how the logic of aggregation guided practices leading to its coalescence. My purpose is to re-examine the aggregate as a quantitative form of capacity that should be qualitatively reconsidered.
\end{abstract}

Keywords: aggregation, Brazil, collectives, future, political form, promises, water

A significant tradition in political and environmental anthropology has documented the structural inequalities and transnational networks through which 'nature' is produced (Bakker 2010; Hayden 2003; Mosse 2003; West 2006). In the case of water, scholars have documented the fraught and unequal implications of material scarcity and excess, and of its commodification or recognition as a right (Aiyer 2007; Anand 2011; Ballestero 2015; Barnes 2014; Carse 2012; Morita 2016). Antina von Schnitzler (2016), for instance, calls attention to how the administrative governance of water infrastructures and service delivery are the grounds on which rights and obligations are adjudicated and the techno-politics of citizenship are negotiated. A large part of these negotiations happens in what she terms an 'administrative interface', the 
material space where citizens and public officials encounter each other. This article is located in that interface in the state of Ceará, Northeast Brazil. It examines the attempts of a [End page 31] set of public officials, civil servants and non-governmental organizations (NGOs) to refigure the ways in which water is collectively managed and organized. It traces an experiment that relies upon personal commitments to care for water as the means to create a collective interface that is different from the state. That formation is imagined as an aggregate, a type of flexible gathering whose existence does not depend on membership or identification. The aggregate is a peculiar construction that is scalable, while remaining context- and scale-specific. The rest of this article examines how that collective was produced, what its constituent units were and how the logic of aggregation allowed for its coalescence. My purpose is to re-examine the aggregate as a quantitative form that demands a qualitative reconsideration.

Ceará's Water Pact (WP) began with the commitment of a group of technical personnel with strong ties to the public sector to break with history. That history was characterized by the ambition of solving water scarcity problems by 'modernizing' infrastructure, institutions and the legal architecture of water. When these technical personnel envisioned the WP in 2008, they imagined that it would not follow the most recent set of reforms conducted in the 1990s. At that time, the state increased its capacity to store, move and charge for water. Technocrats also put in place a series of mechanisms to generate more technical knowledge and clearly define new water use rights.

While historically clientelist practices, large infrastructures and new regulations had become sedimented as unavoidable means to deal with water scarcity, after the 1990s reforms the organizers of the Pact amassed enough support for a new strategy. They hoped to tap into a different resource: people's capacity to care. They wanted to change Ceará's water landscape by resorting to an everyday sense of ethical action that would increase the State's capacity to care for water. Such capacity implied that every member of society would meet their ethical obligation to conserve and use water rationally and according to her own context. If living with scarcity, a person would help raise awareness of the need to save water. If facing pollution issues, a person would promote more environmentally healthy technologies. If wasting water due to inefficient technologies, a person would seek more appropriate techniques. The Pact organizers believed that moving away from the law and infrastructure as starting points would foster people's intimate and universal capacity to care, allowing them to articulate resources and knowledge in novel ways.

Three principles guided the Pact organizers' work. First, the Pact began from the idea that Ceará already had knowledge and solutions in its midst. What was missing was articulating knowledge, technical resources and personnel around a clear purpose. Second, organizers envisioned the Pact as a way of bringing 'society' together around water issues. Rather than putting responsibility for water on a small number of organizations, the Pact would make water a 'transversal' concern. This implied that ordinary citizens would be at the core of the Pact. But this principle proved elusive. Throughout the Pact's implementation, the more events the organizers conducted, the clearer it became that the Pact was mainly able to find the 'state' rather 
than the citizens who would represent 'society'. In an unexpected turn, the Pact's search for society led them to the state in the shape of its local, regional and state-wide representatives. [End page 32] Third, the Pact organizers conducted a series of public promise-making rituals whereby participants would commit to act ethically and do what was necessary to work with and through water in a more responsible way. These public meetings held throughout Ceará yielded large numbers of promises, first verbally uttered, then written on slips of paper, and finally entered into electronic documents. At the centre of the aggregate were their promises, a new type of interface this time between public actors and water itself.

Anthropologists and other social commentators have produced a number of concepts to help describe collectives and their capacity to act. The idea of a network, for example, has been used to explain the associations, connections and disconnects that lead to particular scientific and political capacities (Latour 2005; Strathern 1996). 'Assemblages' is used to highlight fleeting globalized formations with the power to redefine and redistribute political and economic capacities (Collier and Ong 2005). The concept of the multitude signals an unformed yet powerful collective with a revolutionary potential that is always at the verge of being actualized (Hardt and Negri 2005). And, of course, more classic notions such as nation-state (B. Anderson 1991; Bhabha 1994), community (Hayden 2003) and tribe (Malinowski [1926] 1966) have been used to describe collective capacities to intervene, actively or passively, in the world.

As a social form, the Pact contradicts much of what has been attractive about these notions, namely the different degrees of belonging they imply. In the Pact there is nothing to belong to. Instead, collectivity is built through a flexible and transient form of gathering that does not require participants to subscribe to any larger entity (for another articulation of political form, see Ballestero 2012). The Pact does not demand affiliation or membership. Rather than creating a whole, the Pact works by way of aggregation, gathering elements not seen as naturally belonging together into loose formations that are easy to assemble and disassemble.

In anthropology, 'aggregates' have historically had a negative resonance. They are often taken as constructions that dismiss social ties, erasing and homogenizing difference. During the heyday of structuralist thought, anthropologists used aggregates to map the shared cultural traits of collectives grouped under a 'single' culture or ethnicity. But this use of aggregation soon came to an end. Fredrik Barth, for instance, challenged the idea that ethnic groups were 'aggregates of people who essentially share a common culture' (Barth 1998: 9). Barth questioned the utility of defining cultural groups through lists of cultural characteristics and traits. On the contrary, he argued, the existence of an 'ethnic group' is better understood by tracing the changing boundaries between one group and another. Those boundaries allowed anthropologists to see cultural groups as entities that changed over time, as opposed to static accumulations of traits. Barth's challenge to aggregation as a static concept was methodological. He argued for studying processes rather than lists. Barth's thinking facilitated the transition of anthropology towards new theoretical approaches, and aggregation was soon abandoned as both empirical fact and analytic concept (Turner 1995; Gennep 1960; Guyer 1999). 
Yet, in the twenty-first century, aggregation has regained relevance as a native concept (Anderson 2011; Coddington 2015) and as a political form (Juris 2012). [End page 33] Today, rather than constituting stable wholes, aggregates are means to let unstable differences proliferate. Aggregates allow people to sidestep the problem of fixed and contradictory allegiances. The creation of collectives through aggregation does not limit the formations that people can potentially be a part of. On the contrary, aggregates allow people to participate in loose and temporary formations that can be done and undone according to different political, affective or epistemic affinities. If aggregate lists of traits were dismissed as ways to describe collectives because of their lack of attention to dynamic change, people's self-awareness of the speed and proliferation of change now makes aggregates helpful for tracking accelerated shifts in social organization.

Consider one type of aggregate that does not necessarily depend on intention: the database. Through endless databases built on dimensions (traits) of our social experience, those of us who are digitally tracked have become always already aggregated entities, regardless of our intention. Evelyn Ruppert (2012) calls attention to this phenomenon. She argues that rather than thinking in terms of how databases are surveillance of predefined categories and identities, we need to think of these technocratic infrastructures as topological aggregates of people's 'interactions, transactions, performance, activity and movements in relation to government' (Ruppert 2012: 119). Rather than given, aggregates are done and undone according to particular methods and questions. Commonalities are plucked and counted selectively for a specific purpose. The results they generate can be easily formed and dissolved. Not surprisingly, private corporations, especially those working across geographical boundaries, also actively use aggregation as a business strategy. For example, a prominent business magazine exhorts its readers, 'instead of treating geographically separate markets as distinct revenue pools, companies can aggregate these sales across time zones, nationalities, cultures, social networks and interests to serve truly global customer segments' (Borchardt et al. 2011: 21). Thus, as a preferred social form in the contemporary (Rabinow 2009), the aggregate becomes a generative strategy for producing novel capitalist, affective and political possibilities. ${ }^{1}$ It is not surprising, then, that in Northeast Brazil the aggregate is also used to try to shape the future for water.

By tracing the making of this aggregate, I want to argue for a qualitative reconsideration of aggregation as a social form, particularly as a way to generate capacity. ${ }^{2}$ The concept of aggregation helps us see the productivity of the Pact as a collective of commitments that does not claim any form of wholeness; as a plural construction that combines the multiplicity of its units without any aspiration to their amalgamation. The Pact is an aggregate that gathers without claiming to achieve unity. It selectively enrols the participants' willingness to make a promise to care for water, nothing more and nothing less. The remainder of this article traces the making of such a gathering, emphasizing the ideas that go into its construction. I focus on the assumptions that make state officials and consultants working at the administrative interface of water commit to this social form to increase the state's capacity to care for water in a place like Ceará. 
My argument begins with an examination of the historical context from which the Pact emerges: its environmental and political conditions of possibility. I then focus on the methods necessary to generate promises and offer a few examples of how they are [End page 34] made and how their contents are distilled depending on whether they travel across scales or stay tied to one location. This analysis of the promise, the fundamental unit being accumulated in the Pact, takes us to the analysis of form and description as ways to intervene in collective affairs. I end with an illustration that compares two visualizations of aggregates: on the one hand Hobbes' Leviathan, and on the other a digital image produced by Andy Lomas, an artist who uses mathematics and philosophy to generate aggregates.

\section{A pact in a dry landscape}

As part of the semi-arid drought triangle of Northeast Brazil, Ceará is seen in Brazil as a land of stark poverty. The region has the second-worst well-being indicators in the country - second only to Amazonia. Historically vulnerable to the politics of water scarcity (Nelson and Finan 2009), residents of Ceará have seen a parade of ideas and projects, from rain harvesting to household water tanks, march through their neighbourhoods announcing definitive solutions to their historic exclusion from basic water infrastructures (Lemos 2003; Arons 2004). But despite its failure to provide universal access to water and its reputation as a 'backward' state, Ceará is also regarded as exemplary by specialized water institutions (do Amaral Filho 2003). During the 1990s, a reform, partially funded by the World Bank, modernized the state's 'outdated' water sector, with results often praised as exemplary disruptions of the dramatic water future that awaited the state (Simpson 2003). In fact, that reform, which was prior to similar institutional overhauls in the south and south-eastern industrial poles of Brazil, led water experts across the country to think of Ceará's professional circles as pioneers of water innovation. These innovations, according to many in the public sector, are the reason why the extreme multiyear drought the state has been experiencing since 2012 has not had the brutal social and environmental consequences characteristic of the Northeast's past.

But the success of the previous reforms could not turn around the legacy of inequalities and water scarcities that characterizes Ceará. A large proportion of the urban population continues to buy water in bulk from 'horse-drawn carts, motorized tanks, or from people who walk around the streets with large cans of water' (Caprara et al. 2009: S128). In the rural areas, droughts continue to hit vulnerable populations despite public and private experiments in securing continuous access in times of scarcity. Notwithstanding the inauguration in 2002 of the state's largest reservoir, the Açude Castanhão, water scarcity continues to lurk in people's memories and everyday experiences. By 2016, the state's water infrastructure had been pushed to the limit, with reservoirs at their lowest levels in thirty years.

Back in the 2000s, congressional representatives saw the state as being in something of a stalemate, unable to resolve its water access gaps and losing its innovative edge on water issues. After much discussion about new water laws and new institutional reforms, Congress decided to 
adopt a more fluid governance technology. In 2007 they officially inaugurated the Council for Advanced Studies and Strategic Issues with the mission of reducing the distance that separated citizens from their congressional [End page 35] representatives. The Council was charged with identifying strategic state-wide challenges and producing recommendations on how to confront those challenges. The Council's first responsibility was to promote an inclusive, state-wide dialogue to analyse the region's persistent water problems and determine future actions.

Against this background and over approximately four years (2007-2011), the Council worked to construct the Water Pact (WP). Although formally led by Congress, in practice the Council's executive director, Ernesto, developed the Pact process along with a group of consultants with long histories of water-related technical activism, combining diverse knowledge coming from academia, NGOs and public institutions. The team hoped to differentiate the Pact from other 'technical fixes' where authorities retained planning and decision-making powers. Practically, the Pact would ask for people's commitment to solve the imminent problems that water scarcity, pollution and climate change posed. Methodologically, the Pact consisted of a series of public rituals where participants would publicly make pledges to care for water. Materially, the Pact assembled prodigious quantities of written records, later exhibited as published documents and PowerPoint presentations, to openly display people's commitments. Although the organizers held sophisticated views on water issues, they refrained from actively imprinting those views on the Pact's contents to avoid imposing what they saw as extraneous concerns on promises that had to be context-specific. In their view, the methodology of the Pact could be pre-designed. Its contents, however, could not; this had to be determined locally.

By 2009, with almost eight thousand participants and eighty-six institutions involved, the Pact-making phase was brought to an end (Assembleia Legislativa do Estado do Ceará and Conselho de Altos Estudos e Assuntos Estratégicos 2009: 17). More than two hundred participatory events, an unimaginable number of intimate interactions, and rituals of political prestige gave shape to the aggregate that would multiply the state's capacity to care for water in ways that conventional state-centred and technical interventions could not. The Pact team put their faith in associating large numbers of people, mostly public servants but including some citizens as well, tapping into their sentiments and extracting promises for quotidian care for water, as a way to redraw the limits of the possible. All of this took place against the disbelief of many water managers in the public sector, who saw the Pact as an unnecessary waste of resources and a duplication of the work that water agencies were already doing through watershed planning efforts.

\section{Methods of possibility}

When I asked Rebecca, a sociologist in the organizing team, what exactly the Pact was, she answered by noting the difficulty in articulating a definition. 'The Pact', she said, 'is not a thing or a government plan, but a framework that will survive governmental changes and effect more perennial commitments'. It will 'go beyond political preferences to determine paths to be 
followed regardless of who comes to power'. Rebecca's invocation of a path is not accidental. In a state where lasting commitments are embodied in concrete structures, such as canals, reservoirs and irrigation districts, [End page 36] her projection of the Pact into the future required infrastructural analogies. During our conversation, Rebecca explained how a shared definition of this path not only did not exist but was somewhat irrelevant. In fact, she emphasized it was not important to ask what the Pact was, but to figure out how to pact; if the Pact was going to leave a lasting mark, it would be because of the method of its construction (see also Miyazaki 2004).

Stressing how important it was that I understood the methodology they had invented, Rebecca asked for my memory stick and saved 'Ernesto's document'. That document was a purified model full of text boxes, arrows and coloured letters that outlined the Pact's methodological phases. It had been put together by Ernesto, the congressionally appointed leader of the Council.

The first phase involved a broad base of participants from universities, water and sanitation companies, research centres and official water, health, education and agricultural agencies who produced a report on the situation of water resources in the state. The report aimed to be the go-to source of information on water issues. When Ernesto presented the document at a public event in 2008 , he described it as a technical document unlike any other because 'ninetyseven institutions and more than five hundred hands, from two hundred and fifty-six técnicos [technical personnel]' helped to write it. Towards the end of a captivating speech, Ernesto proudly quoted Paulo Freire, a Brazilian education philosopher: 'this document is not a mirar but an admirar, which is to look inside with a critical perspective'. The Pact was taking a critical perspective on water issues while collecting all the available information.

The second phase of the Pact consisted of presenting the results of the report and disseminating the methodology that people were expected to use when they conducted their local, regional and state-wide promise-making events. The consultants facilitating the process travelled to the interior of the state to run explanatory meetings where they presented the technical findings of the report - including things like the gap between the demand and availability of water, the quantity of water used in agriculture, the climatological predictions for the next decade, the number of households lacking clean water and so on. They also introduced the methodology people were expected to use once they organized Pact events in their communities. These coordination meetings had between 80 and 150 participants and were all opened by Ernesto and the congressional representative of the area.

The Pact's third phase entailed the actual promise-making events at a variety of scales, beginning with municipal meetings and then at regional and state-wide events. At these events participants sat together to enunciate and write down their promises. The result was a large set of pledges first uttered in small groups, then written on coloured slips of paper or large sheets posted on walls, and finally turned into electronic documents. These promise-making events were temporally ordered in such a way that some promises could be scaled up. First, 156 municipal meetings were held, then representatives from each municipality came together in a series of regional events facilitated again by a Pact team member to establish inter-municipal and 
regional pacts. At this level, institutions could combine resources to fulfil each other's promises and address larger initiatives such as the construction of water treatment plants or solid waste management systems. Finally, representatives from each municipality [End page 37]

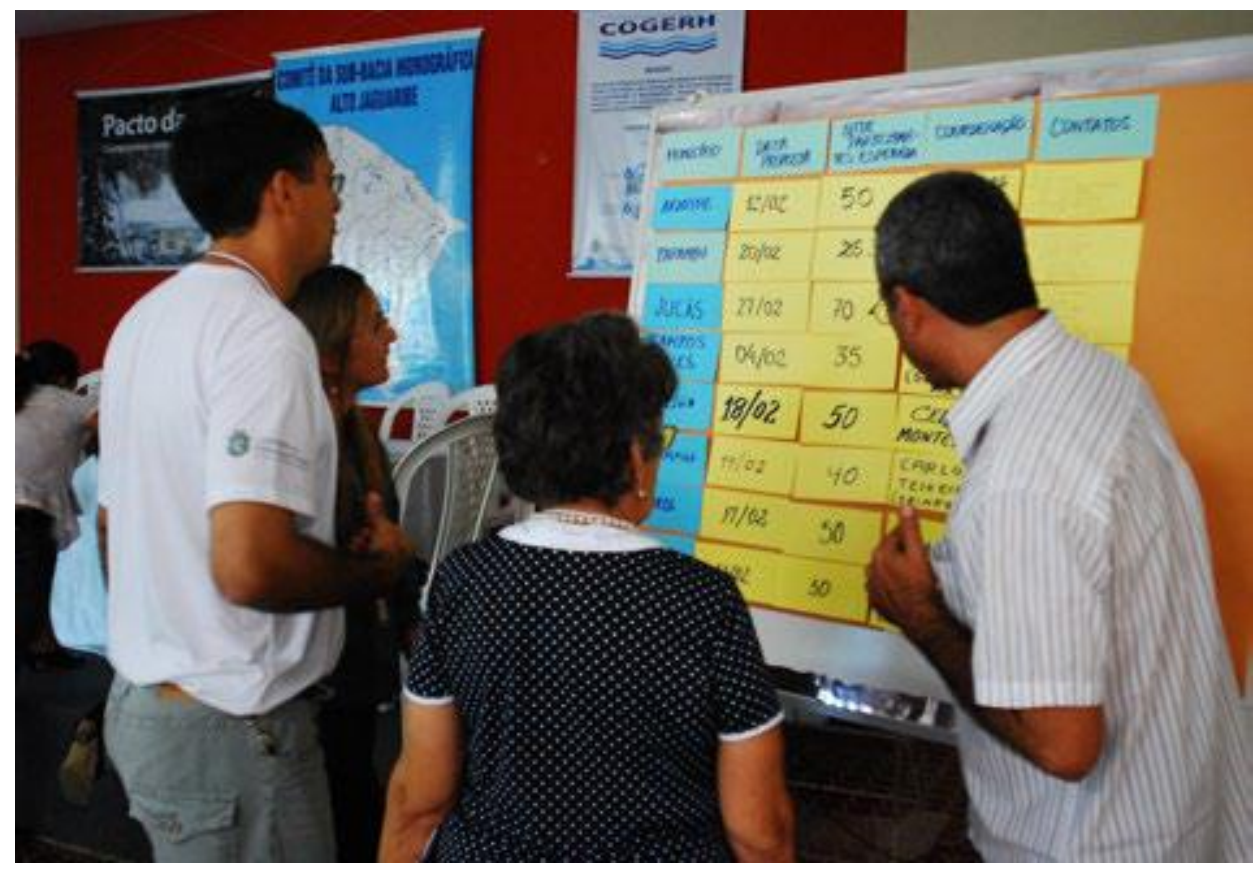

Figure 1. Exhibiting promises on index cards during one of the Pact workshops.

and regional Pact attended a state-wide meeting where macro-pacts were produced, following the same promise-making methods.

The results of these meetings were all systematized into documents that were also called Pacts. The longest document was the state-wide Pact with 408 pages and a 25-page annex that recorded the names of participants, their institutions and the events they attended. By the end of the four-year process, each municipality, alliance of municipalities, watershed and the state as a whole would have their own Pact while being embedded in the Pact of the next scale up.

The purpose of this nested structure was to affirm the moral import of each scale and appreciate its complexity in its own terms, and not from the perspective of a centralized observer. The Pact was not organized to provide a God's eye view from nowhere (Haraway 2004) to oversee the complexity of all water issues across the state, and neither was it susceptible to the surveillance of a panopticon (Foucault 1975) that might police people's fidelity to their promises. The Pact's aggregate structure was, instead, capable of encompassing contradictory flows because it did not presume the need for cohesiveness across scales. This rationale allowed Pact participants to retain their connection to their context, to exist in their own specificity and complexity, without having to fold themselves under an all-encompassing banner as they would if the Pact had been about membership and participation in a more clearly defined entity - a 
committee, an association, a public institution, a governmental agency. Instead of visualizing a single techno-political future, the Pact relied on each pledge, the handshakes that sealed each promise and the personal care people put into them, to unleash people's apparently inherent capacity to care for water. [End page 38]

\section{Distilling promises into words}

Promises, while always touching upon intimate fibres, can take multiple forms. Angela Garcia (2014), for instance, has shown how promises express 'a much larger fabric of moral engagement, including the conflicting responsibilities and punishing demands' that being available to others can impinge upon us. At a less intimate level, and thinking about the futureoriented task of planning as a public activity, Simone Abram and Gisa Weszkalnys argue that governmental planning and policy plans are promises that seem to always be 'slightly out of reach, the ideal outcome always slightly elusive' (2011: 3).

The promises at the core of the Pact were somewhere between these two forms. They were elusive because their future-oriented effects are impossible to fully verify either in the present or at every scale at once. But, at the same time, they were intimate since originally they were all embodied utterances. Each promise emerged as a person-specific pledge, putting the emphasis on the body of the public servant rather than on the state as an abstract entity. But that intimate dimension disappeared as the promises were written down and documented. They changed form as they moved across scales in the Pact-making process.

The Pact methodology was designed to ask participants at the municipal, regional, watershed and state levels to make their own promises. Most participants, however, were involved at only one, or at most two of these scales. A few participants, given their political and technical standing, participated in Pact-making rituals across multiple scales. The promises also had diverse lives. In some cases, a particular promise travelled throughout different meetings at different scales. For the most part, however, the promises had uni-scalar lives; that is, if made at the municipal level or the watershed level, the promises stayed there. But in either case, whether a promise travelled across scales or stayed tied to a particular scale, the Pact-making methodology entailed at its very core a process of distillation. As the utterance of a promise was transformed into an exhibitable, movable unit (in the form of a coloured slip of paper) and ultimately transcribed into an electronic document, the wording of a pledge changed, its form converted.

At all Pact meetings, regardless of their scale, group work was fundamental. Once personal introductions were over and general instructions had been provided, subgroups of people sat together to speak about promises, aspirations, desires. These subgroups were minicosmologies where status, class, gender and history played out with all of their historical overdetermining power. Large landowners or municipal leaders spoke authoritatively; lowerlevel public servants and NGOs offered more tempered statements. A few strong women were able to become main characters; younger ones were relegated to secretarial tasks. In a few cases, 
subversions took place whereby farmers became outspoken and church NGOs challenged the reasons municipal workers provided for not offering to do much. In all cases, however, after some discussion people wrote down their commitments, making them fit onto the slips of paper they were instructed to use. The material limits of the slips, their size, combined with the instruction that only one promise could be inscribed in each slip, resulted in short, declarative statements such as the following: [End page 39]

- I can make sure that we include environmental education programmes in our Municipality.

- I will fight to get the resources to expand the water channel the municipality has been planning to build for three years.

- I will lobby my fellow health workers at the regional health directorate to start talking about water conservation with patients.

- I will hurry up the training programme we have on the books to share information about more efficient irrigation technologies with farmers.

This first moment of inscription was a qualitative distillation of the content of the promises. The richness of the group discussion was concentrated into a short statement. The slips of paper holding the statements were immediately exhibited on the wall, or laid out on the table if the group was small enough. In many cases, the promises ended their procedural life there. They were directly transcribed and remained as part of the local Pact-making exercise.

If the promises entailed actions that touched upon larger scales (watershed, or even the state as a whole), they continued their life. In order to make the particular promises from the group travel forward in the process, the statements had to be 'systematized'. Systematization consisted of entering each promise into a Word document that the consultants had previously populated with tables asking what scale the promise belonged to (municipal, regional, state-wide), who the promise maker was, and what other institutions could be invited to support its implementation. That task entailed another distillation of the promises into a new format. Throughout those conversions, what originally were textured, place- and person-specific commitments became generic statements in policy language, invoking ongoing public programmes and policies, and highlighting the institutions and organizations people worked for. Thus, what were highly specific statements became general declarations that looked like this:

- Attend the meetings at Solonópole, Potiretama and Iracema [names of small cities], along with representatives of EMATERCE [another governmental agency], and provide the necessary water-related information to allow them to make informed decisions. By: Almeida (Head of the Water Management Company).

- Conduct pedagogical workshops in public schools and the broader education community about the adequate use of water, 21 events, led by pedagogical coordinator of each school. By: Municipal Education Secretariat. 
- Train agricultural engineers, foresters, agricultural technicians and rural training managers on organic agriculture, alternative plague management, 184 events, one per municipality. By: Agriculture Secretariat.

In this documentation process, the evidence of the intimacy of the promise, the 'I' in the statement, was gradually shaved off. The promise was distilled so that it could easily travel across policy-making and administrative scales and institutions. The promises were not necessarily made more abstract. If you only took into consideration the published Pact documents, it could seem that way - but bear in mind that each municipality and watershed had its own Pact, with its own documentation, that [End page 40] sometimes included only the collection of the slips of paper, or a binder where a printout of individual pledges was kept.

The Pact organizers, the consulting team, did not have any way to follow up, monitor or evaluate these promises. And that was precisely what they hoped for. The idea of the Pact was that each scale would have promises made and documented in the form that seemed appropriate to each scale. State-wide documents would have policy-friendly language and would look like formal publications; municipal pacts would keep a more specific language and would have a more flexible publication form.

\section{Capacity to intervene: describing the aggregate}

Marilyn Strathern (2014: 23-24) has noted that, in welfare bureaucracies, 'interventions in the world of affairs rest on describing what is happening ... description itself is an intervention'. Inspired by the legacies of welfare democracies, the Pact's capacity to intervene also depends on its descriptions of itself. Because of its aggregate form, the Pact describes itself through the promises of which it is made, rather than through a unified narrative of a future vision or a policy prescription. First uttered, then documented on slips of paper, then in Microsoft Word tables, and finally printed in documents, its descriptive form is not narrative but the form of the list. The final Pact documents are, in a way, nothing more than rolling lists associating aspirations with responsibilities. They are 'distillations of the maps of activity, accumulation, sociability, enterprise [and] aspiration that motivate action in the widest sense' (Philips 2012: 96). The lists of promises in the Pact condense thick histories and imaginaries of futurity -while mediating both through the promise, as a special form of description.

The Pact's reliance on lists as a form of description is due, in part, to the quality of the promiseas an utterance that is unquestionable across scales. The promise made at the municipal level is presumed appropriate to its context, and hence not subject to evaluation from the point of view of another scale (e.g. the watershed or the state), so an expanded narrative to explain its adequacy is unnecessary. The promise is a descriptive intervention that can only be evaluated at the scale of its production: only those who made it can assess it. Presumably, promise makers need no narrative description of something they already know. For that reason, each listed promise is valued, and shielded, by way of its context specificity. The effect of this valuation of 
context is that the documentation of the Pact is taken as intrinsically legitimate and, in a sense, keeps each promise sealed from critique unless that critique comes from the same people making the promise, or others with similar links to a particular context. This is a form of contextual legitimacy that Pact-makers believe builds capacity to care in a way that other political forms cannot. The commitment to that legitimacy requires organizers to work through flexible aggregation and not through narrative unity. To be sure, this makes the Pact precarious, dependent on the intimacy of the utterance for any enforceability. And yet that precariousness is also its potential strength. A promise kept, as anthropologists have shown, has the power to enliven and deepen social relations and forms of collective dependence (Mauss 1967). This contradictory potential, which resides very much in its form, is what characterizes the Pact as a different kind of intervention. [End page 41]

\section{A visual form of aggregation}

One of the claims to power of the Pact is that it brought together more than eight thousand participants. Yet its potential rests less on quantity than on how the promises of those eight thousand participants were aggregated. What makes the Pact interesting is that its form has the capacity to make a promise scalable and, at the same time, allow it to remain faithful to its particular scale and context specificities. If there is any potential in the Pact, it is tied to the rich and multi-scalar lives the promises can have. These promises are neither intimate ethical obligations to care for one another of the sort that Angela Garcia describes, nor completely elusive promises that fly away from any personal sense of responsibility as Abram and Weszkalnys note. The Pact promises are more than empty statements, but less than deep affective pledges to surrender to others. Their social significance is in their collectivity, their coming together as a gathering made up of place- and scale-specific social relations: a construction that is enacted as people follow a set of instructions, make verbal promises, write them on pieces of paper, come together to see them exhibited on walls, receive electronic documents with their transcription, come together again for more meetings at different scales, remind each other of the coffee they had together at the only local pact meeting they attended, or of the memorable joke that somebody told that day.

If the methodological logic that guides the Pact relies on the identification of promises that can be grouped and selectively gathered, it is not a logic of coarse accumulation that aims to add parts until they can complete a whole. The aggregate of the Pact is not an aggregate of individuals, it is a gathering of water-related promises. But, as we saw, each promise goes through a process of distillation, even transformation. These two logics - the logic of aggregation as a summation of individual entities, and the logic of aggregation as a gathering following a particular set of instructions - can be visualized when comparing two images. One is a classic in political theory, the other is closer to algorithmic and mathematic forms of aggregation.

This first image relies on images of addition to achieve unity. This peculiar sense is illustrated in the work of Thomas Hobbes, specifically his Leviathan, or The Matter, Forme, and 
Power of a Commonwealth Ecclesiasticall and Civill ([1651] 1991). In this image, we can see how the political aggregate is an all-encompassing whole where the liberal individual is subsumed under the state as a single, unified entity. In the illustration (Figure 2), Leviathan is composed of the sum of whole units, the whole bodies of its subjects. For Leviathan, its constitutive elements are self-evident. The body of the subject is a familiar singularity that suggests her submission, in all of her facets, under the larger body of the ruler. Leviathan is also a clear bounded entity recognizable as a singularity. Yet this political imaginary of the aggregate as encompassing the whole subject is just one of its many possible renderings.

Another image that does not presume the need to incorporate whole and self-evident units has been visualized by Andy Lomas, a digital artist working on images of mathematical and philosophical aggregation (see Figure 3). Unlike Leviathan's image, the details of Lomas's images do not offer their constitutive forms easily. The form of the aggregate is not readily available for recognition; its overall traits are not self-evident. In this photograph, it is difficult to see any uniformity, forcing us to take one step back [End page 42] and ask, at a more abstract level, what quality might be shared among the units in the image so that they can be aggregated.

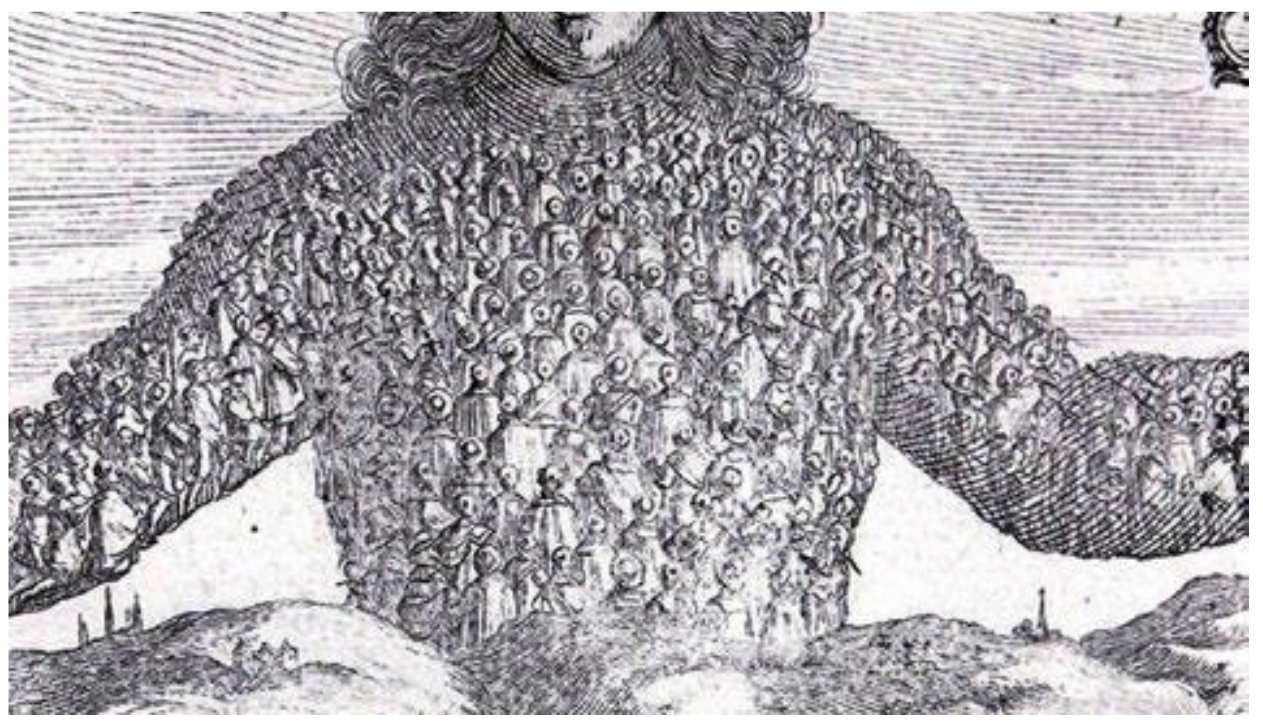

Figure 2. Detail of Leviathan's illustration.

Aggregation necessitates the identification of a shared parameter that makes it methodologically possible rather than operating as a smooth summation into singularity.

In Lomas's work, the property selected as the criterion for aggregation grants a set of elements their temporary gathering. The aggregate is only possible if we know what criteria are used to bring elements together, despite our uncertainty about what those elements are. Even if the methodological steps are predetermined, its ultimate contents are not. Even if we know slips of paper are the first form the promises take, their specific intentions - hurrying up a programme, 
convincing others to teach environmental education, lobbying for a water treatment plant - are not self-evident. This type of aggregate is solid and precarious at once; it is a gathering of many, yet not quite a stable single collectivity. The grouping is only possible because of the constant reaffirmation of the selection parameters that make it possible. The moment our attention shifts from those selection criteria, the possibility of perceiving the aggregate disappears in front of our very eyes.

The Pact resembles Lomas's images more than Hobbes' Leviathan. Its power to augment political capacity is believed to lie in its selectivity, in its capacity to collect and activate a peculiar moral commitment to water without aspiring for its participants to identify holistically with the Pact, much less requiring any form of membership from them. But in order to make that aggregation possible, there is a criterion that needs to be met. A promise needs to be inscribed onto a slip of paper; it is that initial distillation into a declarative statement that allows for the flexible bringing together of promises that share nothing in common content-wise. The Pact's promise of increasing society's capacity to care depends on the possibility of aggregating the form of promises as something that yields collective power to act. It also depends on the exclusion of [End page 43] those commitments that do not abide by that form. That capacity to selectively and temporarily aggregate is its promise.

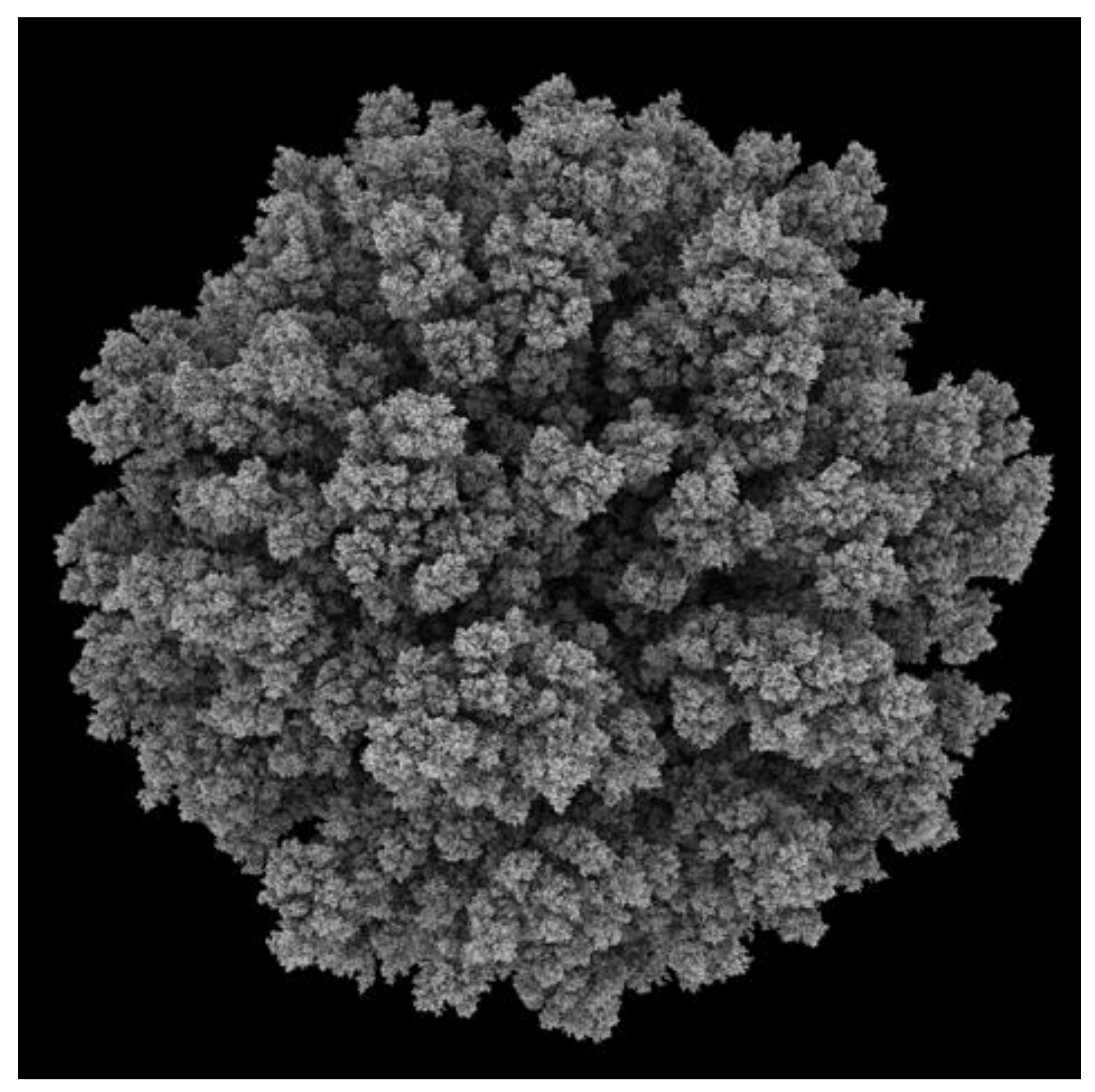

Figure 3. Andy Lomas, Aggregation series. http://www.andylomas.com/. 


\section{Conclusion}

The designers and organizers of the Pact launched the initiative with the expectation that they could break with history. In a sense, their efforts were designed to breed the untimely (Grosz 2004) or to create a future that could yield a different arrangement of social and material forces to secure access to water. Their innovation, as they understand it, is to ask Pact participants for a type of commitment, a promise to care, that is not totalizing and does not require their full allegiance or membership. The Pact can enrol their promises to care for water without requiring their transformation into subjects subsumed under it. [End page 44]

This peculiar form promises to highlight contradiction as a symbol of the adequacy of the effort. If the promises people make across different scales seem not to fit together and sometimes contradict each other, the purpose of maintaining the specificity of context would have been achieved. Thus, context specificity and the contradictions derived from it at different scales make the Pact a collective that can never be glossed as a unit. The conveners of the Pact see it as a social formation that is open to multiplicity rather than a mechanism for transforming differences into commonalities. This is a political form that promises to yield a type of political affect that is somewhere between intimate and elusive: a gathering predicated upon the possibility of mobilizing 'society', even if that possibility is unenforceable and unverifiable. This is the politicization of care as a bureaucratically decentralized form of human-material ordering. Here, care for water as a form of politics only survives if imagined at different scalar levels and for each social actor in her own particularity.

In Ceará, the launching of this political form required a quantitative aesthetics that privileges aggregation as a method of gathering people's capacity to care. The aggregate is a political form conceived to break with a more conventional political history. It is an intervention built upon the description of its units, a structure of promises for the proliferation of care without a God's eye view from which to verify its fruition. The Pact is a precarious and powerful form of making quantity work for quality, blurring the boundaries between them and creating a form of 'capacity' that cannot be fully domesticated: the capacity to care for the everyday sustenance of life within one's own surroundings or context. This capacity might yield a different water landscape and a more democratic future, but no guarantees are offered. 


\section{Acknowledgements}

I would like to thank Brit Ross Winthereik, Annelise Riles and Robert Werth for their comments, which helped clarify this article. Thanks are due to Rachel Douglas-Jones and Justin Shaffner for inviting me to the join the 'Hope and Insufficiency: Capacity Building in Ethnographic Comparison' workshop and to all participants for their thought-provoking conversations. And lastly, my deep gratitude to all my Brazilian colleagues and friends for sharing their thinking, ambitions and doubts with me as they sought to produce a more democratic water world. Research for this article was funded by the National Science Foundation and the Wenner-Gren Foundation.

Andrea Ballestero is Assistant Professor of Anthropology at Rice University, Houston, Texas, where she also runs the Ethnography Studio. Recent publications include 'The Ethics of a Formula, Calculating a Financial-Humanitarian Price for Water' (American Ethnologist, 2015) and 'What's in a Percentage? Calculation as the Poetic Translation of Human Rights' (Indiana Journal of Global Legal Studies, 2014).

\section{Notes}

1. Paul Rabinow (2009) defines the contemporary as a moment in which the past is recuperated as a problem space to imagine a new future. The contemporary is characterized by the problematization of concerns that were taken as settled up until recently. That uncertainty makes the contemporary a moment of social emergence rather than of social reproduction.

2. For two different ways of engaging with quantitative forms as qualitatively rich entities, see Verran 2001 and Ballestero 2015. 


\section{References}

Abram, S. and G. Weszkalnys. 2011. 'Anthropologies of Planning: Temporality, Imagination, and Ethnography'. Focaal 61: 3-18.

Aiyer, A. 2007. 'The Allure of the Transnational: Notes on Some Aspects of the Political Economy of Water in India'. Cultural Anthropology 22 (4): 640-658. doi:10.1525/ can.2007.22.4.640.

Anand, N. 2011. 'Pressure: The PoliTechnics of Water Supply in Mumbai'. Cultural Anthropology 26 (4): 542-564. doi:10.1111/j.1548-1360.2011.01111.x.

Anderson, B. 1991. Imagined Communities: Reflections on the Origins and Spread of Nationalism. London: Verso.

Anderson, C. W. 2011. 'What Aggregators Do: Rhetoric, Practices and Cultures of Digital and Analog Evidence in Web-Era Journalism'. Paper read at the 12th International Symposium for Online Journalism, Austin.

Arons, N. G. 2004. Waiting for Rain: The Politics and Poetry of Drought in Northeast Brazil. Tucson: University of Arizona Press.

Assembleia Legislativa do Estado do Ceará, and Conselho de Altos Estudos e Assuntos Estratégicos. 2009. 'Plano Estratégico dos Recursos Hídricos do Ceará'. Ceará: Fortaleza.

Bakker, K. 2010. 'A Political Ecology of Water Privatization'. Studies in Political Economy 70: 35-58.

Ballestero, A. 2012. 'Transparency Short-Circuited: Laughter and Numbers in Costa Rican Water Politics'. PoLAR: Political and Legal Anthropology Review 35 (2): 223-241.

Ballestero, A. 2015. 'The Ethics of a Formula: Calculating a Financial-Humanitarian Price for Water'. American Ethnologist 42 (1): 262-278.

Barnes, J. 2014. Cultivating the Nile: The Everyday Politics of Water in Egypt. Durham, NC: Duke University Press.

Barth, F. 1998. Ethnic Groups and Boundaries: The Social Organization of Culture Difference. Boston, MA: Little Press.

Bhabha, H. K. 1994. The Location of Culture. London: Routledge.

Borchardt, W. G., J. S. Dailey and P. F. Nunes. 2011. 'New Paths to Growth: The Age of Aggregation'. Outlook: The Journal of High-Performance Business Issue 3: 19-27.

Caprara, A., J. Wellington de Oliveira Lima, A. Correia Pequeno Marinho, P. Gondim Calvasina, L. Paes Landim and J. Sommerfeld. 2009. 'Irregular Water Supply, Household Usage and Dengue: A Bio-social Study in the Brazilian Northeast'. Cadernos de Saúde Pública 25 (1): S125-S136.

Carse, A. 2012. 'Nature as Infrastructure: Making and Managing the Panama Canal Watershed'. Social Studies of Science 42 (4): 539-563.

Coddington, M. A. 2015. 'Telling Secondhand Stories: News Aggregation and the Production of Journalistic Knowledge'. Ph.D. diss., University of Texas at Austin.

Collier, S. J. and A. Ong. 2005. 'Global Assemblages, Anthropological Problems'. In A. Ong and S. J. Collier (eds), Global Assemblages: Technology, Politics, and Ethics as Anthropological Problems. Malden: Blackwell, 3-21.

do Amaral Filho, J. 2003. 'Reformas Estruturais e Economia Politica dos Recursos Hidricos no Ceara'. Fortaleza, CE: SEPLAN-IPECE.

Finan, T. J. and D. R. Nelson. 2001. 'Making Rain, Making Roads, Making Do: Public and Private Adaptations to Drought in Ceará, Northeast Brazil'. Climate Research 19 (2): 97 108. 
Foucault, M. 1975. Discipline and Punish: The Birth of the Prison. New York: Vintage Books. Garcia, A. 2014. 'The Promise: On the Morality of the Marginal and the Illicit'. Ethos 42 (1): 51-64.

Gennep, A. van. 1960. The Rites of Passage. 1909, trans. M. B. Vizedom and G.L. Caffee. Chicago: University of Chicago Press.

Grosz, E. 2004. The Nick of Time: Politics, Evolution, and the Untimely. Durham, NC: Duke University Press.

Guyer, J. I. 1999. 'Anthropology: The Study of Social and Cultural Originality'. African Sociological Review/Revue Africaine de Sociologie 3 (2): 30-53.

Haraway, D. 2004. 'Modest_Witness@Second_Millenium'. In D. Haraway (ed.), The Haraway Reader. New York: Routledge, 223-250.

Hardt, M. and A. Negri. 2005. Multitude: War and Democracy in the Age of Empire. New York: Penguin.

Hayden, C. 2003. When Nature Goes Public: The Making and Unmaking of Bioprospecting in Mexico. Princeton: Princeton University Press.

Hobbes, T. [1651] 1991. Leviathan. Cambridge: Cambridge University Press.

Juris, J. S. 2012. 'Reflections on \#Occupy Everywhere: Social Media, Public Space, and Emerging Logics of Aggregation'. American Ethnologist 39 (2): 259-279.

Latour, B. 2005. Reassembling the Social: An Introduction to Actor-Network Theory, Clarendon Lectures in Management Studies. Oxford: Oxford University Press.

Lemos, M. C. 2003. 'A Tale of Two Policies: The Politics of Climate Forecasting and Drought Relief in Ceara, Brazil'. Policy Sciences 36: 101-123.

Malinowski, B. [1926] 1966. Crime and Custom in Savage Society. London: Routledge.

Mauss, M. 1967. The Gift. New York: W. W. Norton.

Miyazaki, H. 2004. The Method of Hope. Stanford: Stanford University Press.

Morita, A. 2016. 'Infrastructuring Amphibious Space: The Interplay of Aquatic and Terrestrial Infrastructures in the Chao Phraya Delta in Thailand'. Science as Culture 25 (1): 117140.

Mosse, D. 2003. The Rule of Water: Statecraft, Ecology and Collective Action in South India. Oxford: Oxford University Press.

Nelson, D. R. and T. J. Finan. 2009. 'Praying for Drought: Persistent Vulnerability and the Politics of Patronage in Ceará, Northeast Brazil’. American Anthropologist 111 (3): 302-316.

Philips, A. 2012. 'List'. In C. Lury and N. Wakeford (eds), Inventive Methods: The Happening of the Social. London: Routledge, 96-109.

Rabinow, P. 2009. Marking Time: On the Anthropology of the Contemporary. Princeton: Princeton University Press.

Ruppert, E. 2012. 'The Governmental Topologies of Database Devices'. Theory, Culture \& Society 29 (4-5): 116-136. doi:10.1177/0263276412439428.

Simpson, L. D. 2003. 'Integrated Water Resources Management, Ceara, Brazil'. Washington, DC: World Bank.

Strathern, M. 1996. 'Cutting the Network'. Journal of the Royal Anthropological Institute N.S. (2): 517-535.

Strathern, M. 2014. 'Anthropological Reasoning: Some Threads of Thought'. HAU: Journal of Ethnographic Theory 4 (3): 23-37.

Turner, V. 1995. The Ritual Process: Structure and Anti-Structure. New York: Aldine de 
Gruyter.

Verran, H. 2001. Science and African Logic. Chicago: University of Chicago Press.

von Schnitzler, A. 2016. Democracy's Infrastructure: Techno-Politics and Protest after Apartheid. Princeton, NJ: Princeton University Press.

West, P. 2006. Conservation Is Our Government Now: The Politics of Ecology in Papua New Guinea. Durham, NC: Duke University Press. 
